habitat of the walia, gelada and klipspringer and a description of their ecological separation.

The book is slightly marred by overcomplex presentation of the data and by a confused use of the terms 'factor' and 'parameter' in chapter 8 and throughout. Nevertheless this is essential reading for wildlife biologists and ecologists, and the non-mathematical descriptive sections are of potential interest to a wide public, especially those interested in the flora and fauna of Africa.

PAUL MUNTON

Rare and Endangered Plants of New Zealand, by D.R. Given. A.H. \& A.W. Reed, $\$ 22.95$.

Many books have been written about rare and endangered animals, particularly birds and mammals, with the aim of stimulating public interest and concern. The plight of plants has been less well publicised although there have been several recent red data compilations at an international and national level.

David Given successfully brings forward another approach to our understanding of the subject. He points out that plant species in New Zealand (as elsewhere) have evolved and colonised without man's assistance and are an irreplaceable part of New Zealand's heritage. Whether they become a vanishing heritage or survive and prosper is, however, in man's hands. The challenge is great, for it is estimated that one in ten of New Zealand's native plant species can be described as at risk and simple human ignorance is often responsible. Given has examined broad habitats describing threatened plants in coastal areas, open and rocky places, wetlands, forest and scrub, islands and alpine regions. The effectiveness of this approach obviously rests on a detailed and comprehensive understanding of the floristics and ecology of the vegetation, and David Given has a familiarity with the New Zealand vegetation which must be the envy of many. He has been able to describe the occurrence and distribution of threatened plants in a habitat context and clearly defines the threats and how they might be ameliorated.

One problem facing workers anxious to stimulate public interest is the extent to which detailed information on localities is provided. It is important to encourage people to find new occurrences but there are all too many examples of unscrupulous collectors using such information to the decimation of the plant, and Given has adopted the policy of not providing detailed site records; distribution is given only in general terms.

The book contains valuable chapters on the concepts of rarity and strategies for survival. The final chapter 'The Personal Challenge' presents the author's own philosophy on conservation, and clearly reveals that David Given is not only a leading authority on rare and threatened New Zealand plants but a dedicated conservationist.

JOHN LEIGH

\title{
The Biological Aspects of Rare Plant Conservation, edited by Hugh Synge. Wiley, $£ 30.00$.
}

These proceedings of an international conference, held at Cambridge in July 1980, have been brought through to publication with commendable speed. It grew out of the concern of taxonomists at the increasing speed of extinction of rare species, and included ecologists, phytosociologists and practising conservationists.

The first quarter of the text is a survey and assessment of rare and threatened species, with contributions from North America, the USSR, India, Australia, New Zealand and Europe. A shorter section on the crucial topic of Tropical Forests is followed by a series of papers on the problems of what really constitutes rarity and how rare plant populations can be monitored, and a further ten papers on ecological studies of rare 


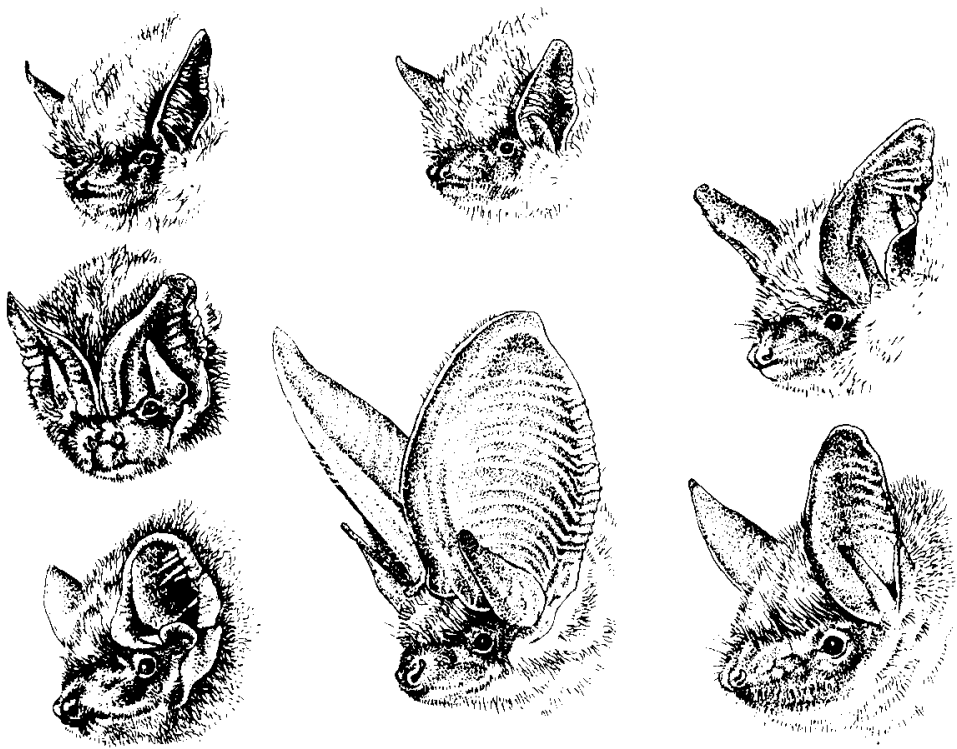

SEVEN RARE BRITISH BATS: left to right, top whiskered and Brandt's; middle barbastelle and Bechstein's; bottom Leisler's, grey long-eared and mouse-eared. A drawing by Priscilla Barrett, reproduced from the RSPCA Book of British Mammals, edited by C.L. Boyle, ffPS Vice-President, (Collins, £8.75), which will be reviewed in the next Oryx.

plants. This section deals purely with African and British examples. Three papers on introductions, all in Britain, explore this controversial problem in rather different ways, and there are seven papers on various aspects of protected areas for rare plants.

This conference clearly served a useful purpose in bringing together botanists from many countries to discuss conservation problems of mutual concern. Perhaps inevitably the published proceedings are an uneasy mixture of pure science and applied conservation. It would be impossible to discuss all the 42 papers in a brief review, but a few caught my interest: from the Survey and Assessment section, those of Nilsson.on threatened Swedish plants, and Crompton on rare plants in eastern England, and the panel discussion on the too often neglected topic of conservation of lower plants is very important. In the discussions of rarity as a concept, John Harper's paper is predictably thought-provoking, while Margaret Bradshaw gives a graphic account of one of the few examples, that of Teesdale, of long-term monitoring of rare plants. Several of the ecological studies are very valuable, and the problem of introduction is well aired. Perhaps the suggestions of Ranwell that introductions of coastal plants, including aliens, could be increased, deserve further discussion.

All botanists concerned with the future of wild plants should read this book, and if it encourages some to take positive steps to study, understand, and eventually conserve some rare species it will achieve its purpose. All royalties go to ffPS plant projects.

S.R.J. WOODELL

\section{International Organisations and the Conservation of Nature, by Robert Boardman. Macmillan, $£ 15$.}

The history of institutions can only be brought to life if it is written in terms of the personalities that operated them. This is inevitably largely a history of IUCN. But although Professor Boardman mentions some individuals from time to time - Paul Sarasin, for instance, Julian Huxley, Jean-Paul Harroy, Peter Scott - he in no way discusses IUCN in terms of the succession of able presidents and secretaries who have run it. An analysis of the impact of Harold Coolidge, who unexpectedly became president when Ed Graham died, would have made fascinating reading. An indication 